Trunk Technique: European Association for CardioThoracic Surgery Position and Bologna Experience. Korean J Thorac Cardiovasc Surg. 2017;50(1):1-7. doi: $10.5090 /$ kjtcs.2017.50.1.1

3. Roselli EE, Idrees JJ, Bakaeen FG, et al. Evolution of Simplified Frozen Elephant Trunk Repair for Acute DeBakey Type I Dissection: Midterm Outcomes. Ann Thorac Surg. 2018;105(3):749-755.

doi:10.1016/j.athoracsur.2017.08.037

4. Liakopoulos OJ, Kroener A, Sabashnikov A, et al. Single-center experience with the frozen elephant trunk procedure in 111 patients with complex aortic disease. J Thorac Dis. 2020;12(10):5387-5397. doi:10.21037/jtd-20-1531

5. Damberg A, Schälte $G$, Autschbach $R_{\text {, }}$ Hoffman A. Safety and pitfalls in frozen elephant trunk implantation. Ann Cardiothorac Surg.
2013;2(5):669-676.

doi:10.3978/j.issn.2225319X.2013.09.16

6. Kremer J, Preisner F, Dib B, et al. Aortic arch replacement with frozen elephant trunk technique - a single-center study. J Cardiothorac Surg. 2019;14(1):147. doi:10.1186/s13019-019-0969-9

7. Hohri Y, Yamasaki T, Matsuzaki Y, Hiramatsu T. Early and mid-term outcome of frozen elephant trunk using spinal cord protective perfusion strategy for acute type A aortic dissection. Gen Thorac Cardiovasc Surg. 2020;68(10):1119-1127. doi: $10.1007 / \mathrm{s} 11748-020-01328-z$

8. Frozen elephant trunk does not increase incidence of paraplegia in patients with acute type A aortic dissection - The Journal of Thoracic and Cardiovascular Surgery. Accessed April 13, 2021. https:// www.jtcvs.org/ article/S0022-5223(19)30800-1/fulltext.

\title{
NGHIÊN CỨU KỸ THUÂT GÂY KHAC ĐỜM TRONG CHẨN ĐOÁN LAO PHỔI AFB ÂM TÍNH VÀ MộT Số ĐĂC ĐIỂM LÂM SÀNG, CẬN LÂM SÀNG CỦA BỆNH NHÂN ĐƯợC CHẨN ĐOÁN XÁC ĐỊNH
}

\section{TÓM TẮT}

Đăt vấn đề: Gây khạc đờm đã được chứng minh là phương pháp lấy bệnh phẩm an toàn, dễ thực hiện, giá trị cao, ít xâm lấn, có thể thực hiện lại nhiều lần, giá thành rẻ. Do đó, có thể sử dụng gầy khạc đờm để chẩn đoán lao phổi AFB âm tính - vốn có biểu hiên lâm sàng nghèo nàn, chẩn đoán xác định còn khó khăn, phức tap và thường phải dựa vào kỹ thuât hiên đại tốn kém. Vì vậy chúng tôi thực hiện nghiển cứu này nhằm 2 mục tiêu: 1) Mô tả một số đăc điểm của kỹ thuât gây khac đờm trong chẩn đoán lao phổi AFB âm tính, 2) Phân tích một số đặc điểm lâm sàng, cận lâm sàng của bệnh nhân lao phổi AFB âm tính. Đối tượng và phương pháp nghiên cứu: Thiết kế nghiên cứu mô tả cắt ngang trên những bệnh nhân nghi lao, có ít nhất 2 mâuu đờm thường quy $A F B$ âm tính. Kết quả: có 309 bênh nhân tham gia vào nghiên cứu, trong đó tỷ lệ gẩy khạc đờm thành công là $98,1 \%$. Tỷ lệ có biến chứng là $13,6 \%$ găp biến chứng; biến chứng hay gặp nhất là khó thở nhẹ $(88,1 \%)$. Trong 298 bênh nhân đủ tiêu chuẩn phân tích có 45 bênh nhân được chẩn đoán xác định lao phổi bằng tiêu chuẩn cấy MGIT dương tính với vi khuẩn lao. Kappa giữa 2 phương pháp GKĐ và NSPQ là 0,81 , $\mathrm{p}=0,0000$, hai phương pháp có độ đồng thuận rất tốt. Các triệu chứng lâm sàng như mệt mỏi, gầy sút cân, ra mồ hôi trộm và hình ảnh trên X-quang điển hình

*Bênh Viện Hữu Nghi

**Trướng Đai Hoc Y Hà Nôi

Chịu trách nhiệm chính: Nguyễn Minh Sang

Email: sangmedi@gmail.com

Ngày nhận bài: 24.2.2021

Ngày phản biên khoa hoc: 30.3.2021

Ngày duyệt bài: 9.4.2021

\section{Nguyễn Minh Sang*, Phan Thu Phương**}

như thâm nhiễm, xơ vôi có ý nghĩa trong chẩn đoán lao phổi $(p<0,05)$. Kết luân: Kỹ thuật gây khạc đờm khá an toàn, tỷ lệ lấy được bệnh phẩm rất cao, và có đồng thuận rất tốt với nội soi phế quản trong chẩn đoán lao phổi AFB âm tính. Một số triệu chứng lâm sàng và cận lâm sàng có giá trị trong chẩn đoán lao phối AFB ẩm tính là: mệt mỏi, gây sút cân, ra mồ hô trộm, $X$ quang có hình ảnh thâm nhiếm, hình ảnh xơ vôi.

Từ khóa: Gây khạc đờm, lao phổi AFB âm tính

\section{SUMMARY \\ INDUCED SPUTUM IN DIAGNOSIS OF SMEAR-NEGATIVE PULMONARY TUBERCULOSIS, CLINICAL AND SUBCLINICAL CHARACTERISTICS OF DIAGNOSED PATIENTS}

Background: Induced sputum has been shown to be a safe, easy-to-implement, high-value, low-invasive method that can be repeated and cheaply. Therefore, it can be used to diagnose smear-negative pulmonary tuberculosis, which often had poor clinical symptoms, and difficult in definitive diagnosis, complicated and often requires expensive modern technology. We conducted this study with 2 purposes: 1) Describe some features of the induced sputum technique in smear-negative diagnosis, 2) Analyze some clinical and subclinical characteristics of patients with smearnegative pulmonary tuberculosis. Methods: A crosssectional study design was used in patients suspected pulmonary tuberculosis, who had at least 2 spontaneous sputum smear - negative. Results: 309 patients participated in the study, of which induced sputum successful rate was $98.1 \%$. The rate of complications was $13.6 \%$, the most common one was mild dyspnea (88.1\%). Of the 298 patients eligible for analysis, 45 were diagnosed with pulmonary 
tuberculosis via MGIT (+). The Kappa between induced sputum and bronchoscopy was $0.81, \mathrm{p}=$ 0.0000 , the two methods had almost perfect agreement. Clinical symptoms such as fatigue, weight loss, sweating, and typical X-ray images such as infiltration and calcified fibrosis are significant different in patients with pulmonary tuberulosis $(p<0.05)$. Conclusion: Induced sputum was safe; the successful rate of the procedure was high. Induced sputum had a very good agreement with bronchoscopy on the diagnosis of pulmonary tuberculosis. Some of the valuable clinical and subclinical features in the diagnosis of smear-negative pulmonary tuberculosis were fatigue, weight loss, sweat theft, and X-rays with infiltrated and calcified fibrosis. Keywords: Induced sputum, pulmonary tuberculosis, smear negative

Một số từ viết tắt: $A F B$ : Acid - Fast Bacilli (trực khuẩn kháng toan ), MGIT: mycobacteria growth indicator tube (nuôi cây mycobacteria trong môi trường lỏng), GKĐ: gây khạc đờm, NSPQ: nội soi phế quản.

\section{I. ĐĂT VẤN ĐỀ}

Trong chuyên ngành hô hấp, lấy bệnh phẩm từ đường hô hấp để chẩn đoán và theo dõi điều trị các bệnh lý hô hấp là rất quan trọng. Có rất nhiều phương pháp lấy bệnh phẩm khác nhau như sinh thiết bằng mổ mở, sinh thiết xuyên thành ngực, gây khạc đờm hay nội soi phế quản,... Trong đó, kỹ thuật gây khạc đờm đã được chứng minh là có hiệu quả cao trong chẩn đoán lao phổi tương đương với nội soi phế quản, cao hơn khạc đờm tự nhiên có hướng dẫn và cao hơn dịch dạ dày. Tuy nhiên ở Việt Nam, kỹ thuật GKĐ chưa được ứng dụng nhiều trên lâm sàng.

Theo báo cáo của Chương trình Chống lao Quốc gia năm 2015, tỷ lệ lao AFB âm tính là khá cao, 21,9\%. Tuy nhiên, nhiều bệnh nhân lao AFB âm tính còn chưa được chẩn đoán, đây là một trong những thách thức trong chẩn đoán và điều trị lao hiện nay ở trên thế giới cũng như ở Việt Nam. Vì vậy, việc sử dụng kỹ thuật gây khạc đờm trong chẩn đoán lao phổi $\mathrm{AFB}$ âm tính có thể áp dụng, đem lại nhiều ưu điểm như đô chính xác và an toàn cao, kỹ thuật không quá phức tạp và giá thành tương đối thấp so với các kỹ thuật xâm lấn khác.

Do đó chúng tôi thực hiện nghiên cứu "Nghiên cứu kỹ thuật gây khạc đờm trong chẩn đoán lao phổi $A F B$ âm tính và mốt số đặc điểm lâm sàng, cận lâm sàng của bệnh nhẩn được chẩn đoán xác định" nhằm các mục tiêu chính như sau: 1) Mô tả một số đặc điểm của kỹ thuật gây khạc đờm trong chẩn đoán lao phổi AFB âm tính, 2) Phân tích một số đặc điểm lâm sàng, cận lâm sàng của bệnh nhân lao phổi AFB âm tính.

\section{II. ĐỐI TƯợNG VÀ PHƯƠNG PHÁP NGHIÊN CỨU 2.1. Đối tượng nghiên cứu}

\section{Tiêu chuẩn lựa chon bênh nhân}

1) Các bệnh nhân vào khám hoặc điều trị tại Trung tâm Hô hấp Bệnh viện Bạch Mai, Khoa Hô hấp - Dị ứng Bệnh viện Hữu Nghị; có lâm sàng và $X$ quang nghi lao phổi, có ít nhất 2 mẫu đờm lấy theo phương pháp thường quy âm tính.

2) Đồng ý làm kỹ thuật gây khạc đờm.

3) Độ tuổi $\geq 15$ tuồi.

Tiêu chuân loai trừ. Có chống chi định với các kỹ thuật GKĐ: Trong cơn hen, trong đợt cấp của COPD, suy hô hấp nặng, suy tim mât bù.

2.2. Đia điểm nghiên cứu, thời gian nghiên cứu: Nghiên cứu được tiến hành tại trung tâm Hô hấp Bệnh viện Bạch Mai và Khoa Hô hấp - Dị ứng Bệnh viện Hữu nghị từ tháng 10 năm 2017 đến tháng 1 năm 2021.

2.3. Phương pháp nghiên cứu: Nghiên cứu mô tả trên nhóm bệnh nhân nghi lao phổi $\geq$ 15 tuổi.

Cỡ mẫu: 309 bênh nhân đáp ứng đủ tiểu chuẩn được chọn vào nghiên cứu, trong đó có $262(84,8 \%)$ bệnh nhân tại Bệnh viện Bach Mai và $47(15,2 \%)$ bệnh nhân tại Bệnh viện Hữu Nghị. Có 6 bệnh nhân GKĐ không thành công, còn lại 303 bệnh nhân GKĐ thành công. Trong 303 bệnh nhân GKĐ thành công có 5 bệnh nhân xét nghiệm AFB (+), còn lại 298 bệnh nhân đủ tiêu chuẩn nghiên cứu đặc điểm lâm sàng, cận lâm sàng lao phổi AFB (-).

Các bước tiến hành nghiên cứu:

- Bệnh nhân nghi lao có 2 mẫu đờm khạc theo phương pháp thường quy sẽ được chọn vào nghiên cứu

- Thu thập thông tin về triệu chứng lâm sàng và cận lâm sàng dựa trên mẫu bệnh án thiết kế trước.

- Thực hiên kỹ thuâtt gây khạc đờm, các bênh phẩm lấy được sẽ được làm các xét nghiệm nhuôm soi tìm AFB, Xpert MTB/Rif, nuôi cấy vi khuẩn lao theo phương pháp MGIT.

- Trong trường hợp xét nghiệm AFB âm tính và Xpert MTB/Rif âm tính thì bệnh nhân sẽ được NSPQ nễu bệnh nhân đồng ý.

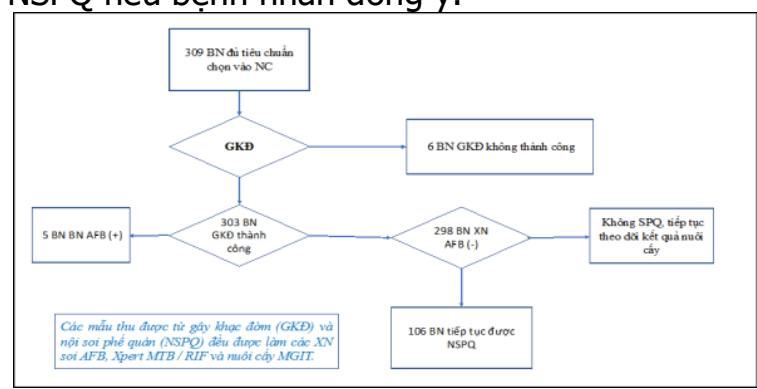

Hình 1: Tóm tắt sơ đồ nghiên cứu

- Bệnh nhân có kết quả xét nghiệm nuôi cấy 
MGIT dương tính với vi khuẩn lao từ bệnh phẩm GKĐ hoặc NSPQ sẽ được chẩn đoán xác định là mắc lao phổi.

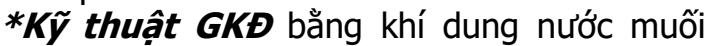
ưu trương: Chúng tôi khí dung natriclorua ưu trương $3 \%$ hoặc $5 \%$ bằng máy khí dung siêu âm Devilbiss 99 Ultraneb sản xuất tại Hoa Kỳ. Dung dịch muối ưu trương $3 \%$ cho những trường hợp có tiền sử hen phế quản, COPD hoặc có triệu chứng khó thở tại thời điểm thực hiện khí dung. Dung dịch muối $5 \%$ sử dụng cho những bệnh nhân không có triệu chứng khó thở, không mắc 1 trong 2 bệnh trên. Cứ 5 phút dừng khí dung 1 lần cho bệnh nhân ho khạc sau đó lại tiếp tục. Kỹ thuật dừng lại khi đã lẩy đủ bệnh phẩm hoặc bênh nhân có tai biến hoăc không dung nạp. Tai biến và xử trí : Tai biến có thể gặp là co thắt phế quản. Sau thủ thuật bệnh nhân được tiếp tục theo dõi sát tại chỗ ít nhất 1 giờ, để đề phòng co thắt phế quản. Nếu có co thắt phế quản thì phải ngừng thủ thuật, khí dung Ventolin $5 \mathrm{mg} 1$ đến 2 nang, thở oxy.

**NSPQ rưa phế quản phế nang chọn lọ: sử dụng hệ thống NSPQ Olympus: ống soi BF $1 T$ 150, nguồn sáng, hệ thống chuyền ghi hình ảnh.

2.5. Xử lý số liệu: Số liệu thu được xử lý trên máy tính, sử dụng các phần mềm SPSS 16.0, STATA 12 (Statacorp LP, TX, USA), các thuật toán $\mathrm{X}^{2}$, T Student, Độ nhậy (Se), độ đặc hiệu (Sp).

2.6. Đạo đức nghiên cứu: Nghiên cứu đã được Hội đồng đạo đức $Y$ học đại học $Y$ Hà nội phể chuẩn.

III. KẾT QUẢ NGHIÊN CỨU

3.1. Đặc điểm kỹ thuâtt gây khạc đờm

3.1.1. Mốt số đăc điểm kỹ thuật GKĐ

Bảng 1. Đặc điểm kỹ thuật GKĐ

Đặc điếm kỹ thuật

BN tham gia nghiên cứu $(\mathbf{N}=309)$

\begin{tabular}{|c|c|}
\hline & \\
\hline GKĐ thành công & $303(98,1 \%)$ \\
\hline KOĐ không thành công & $6(1,9 \%)$ \\
\hline & $\begin{array}{c}66,6 \%(4 / 6) \mathrm{BN} \text { co thắt } \\
\text { phế quản }\end{array}$ \\
\hline không t & $\begin{array}{l}\text { 33,4\% (2/6) Không } \\
\text { dung nap (Bênh nhẩn } \\
\text { buồn nôn, nôn) }\end{array}$ \\
\hline GKÐ & $n=303$ \\
\hline & Mủ đục 175 (57,8\%) \\
\hline Màu & Trong $115(38,9 \%)$ \\
\hline & Lân máu $13(4,3 \%)$ \\
\hline Thời & $\begin{array}{c}27,5 \pm 5,8 \text { phút, thấp } \\
\text { nhất } 5 \text { phút, cao nhất } \\
40 \text { phút }\end{array}$ \\
\hline
\end{tabular}

\begin{tabular}{|l|l|}
\hline Số lần dừng lại đế khạc & $5,13 \pm 1,09$ lần, thấp
\end{tabular} nhất 2 lân, cao nhất 8 lân Muối 5\%: 163 (53,8\%) Muối 3\%: 140 (46,2\%)

Nồng độ muối

Nhận xét: Tỷ lệ thành công (lấy được bệnh phẩm đủ tiêu chuẩn) của GKĐ là rất cao $98,1 \%$. Lý do GKĐ không thành công chủ yếu là do bênh nhân co thắt phế quản (4/6 bệnh nhân). Màu sắc của bệnh phẩm GKĐ có $57,8 \%$ là mủ đục, $38,9 \%$ là dịch trong.

3.1.2. Độ an toàn của kỹ thuật gây khạc đờm

Bảng 2. Độ an toàn của GKÐ

\begin{tabular}{|c|c|}
\hline $\begin{array}{c}\text { Độ an toàn } \\
\text { Khồng có biến } \\
\text { chứng }\end{array}$ & $\mathbf{N}=\mathbf{3 0 9}$ \\
\hline Có biến chứng & $267(86,4 \%)$ \\
\hline \multirow{4}{*}{ Loại biến chứng } & $\begin{array}{c}\text { Khó thơ nhe: } 37 \\
(88,1 \%)\end{array}$ \\
\cline { 2 - 2 } & Suy hô hấp : $3(7,1 \%)$ \\
\cline { 2 - 2 } & Khác (nôn): $2(4,8 \%)$ \\
\cline { 2 - 2 } & Tứ vong : 0 \\
\hline \multirow{3}{*}{ Xử trí biến chứng } & $\begin{array}{c}\text { Dừng khí dung, không } \\
\text { cần xứ trí: } 22(52,4 \%)\end{array}$ \\
\cline { 2 - 2 } & $\begin{array}{c}\text { Thở oxy, khí dung } \\
\text { ventolin: } 20(47,6 \%)\end{array}$ \\
\hline
\end{tabular}

Nhân xét: Tỷ lê có biên chứng là $13,6 \%$ gặp biến chứng; biến chứng hay gặp nhất là khó thở nhe $(88,1 \%)$; phương pháp xử trí biến chứng là dừng khí dung, không cần xử trí $(52,4 \%)$ và thở oxy, khí dung ventolin $(47,6 \%)$.

3.2. Giá trị của kỹ thuất gây khạc đờm trong chẩn đoán lao phổi AFB âm tính. Chúng tôi thu thập được 298 bệnh nhân đủ tiêu chuẩn nghiên cứu đặc điểm lâm sàng, cận lâm sàng lao phổi AFB âm tính.

3.2.1. Kết quả chẩn đoán lao phổi. Bênh nhân được chẩn đoán xác định lao phổi khi bệnh phẩm GKĐ hoặc soi phế quản có kết quả xét nghiệm nuôi cẩy MGIT dương tính với vi khuẩn lao (tiêu chuẩn vàng).

Bảng 3. Kết quả chẩn đoán xác định lao phổi

\begin{tabular}{|c|c|c|}
\hline & $\mathbf{N}$ & Tỷ lệ \% \\
\hline MGIT MTB GKĐ $(+)$ & $43 / 298$ & 14,4 \\
\hline MGIT MTB NSPQ (+) & $9 / 106$ & 8,5 \\
\hline $\begin{array}{c}\text { Chấn đoán xác định } \\
\text { lao phổi }\end{array}$ & $45 / 298$ & 15,1 \\
\hline
\end{tabular}

Nhân xét: Chẩn đoán xác định lao phổi tại thời điểm nghiên cứu là $15,1 \%$.

3.2.2. So sánh kết quả nuôi cây MGIT của bệnh phẩm lây kỹ thuật pháp gây khạc đờm và nội soi phế quản. Chúng tôi thu được 106 bệnh nhân được thực hiện đủ cả 2 kỹ thuật lấy bệnh phẩm: GKĐ và NSPQ. 
Bảng 4. So sánh kêt quả chẩn đoán lao phổi của GKÐ và NSPQ

\begin{tabular}{|c|c|c|c|c|c|c|}
\hline \multirow{2}{*}{ Xét nghiệm } & \multicolumn{2}{|c|}{ MGIT MTB NSPQ (+) } & \multicolumn{2}{c|}{ MGIT MTB NSPQ (-) } & \multicolumn{2}{c|}{ Chung } \\
\cline { 2 - 7 } & $\mathbf{n}$ & $\mathbf{0}$ & $\mathbf{n}$ & $\mathbf{\%}$ & $\mathbf{n}$ & $\mathbf{\%}$ \\
\hline MGIT MTB GKÐ (+) & $\mathbf{7}$ & 6,60 & $\mathbf{1}$ & 0,94 & $\mathbf{8}$ & 7,55 \\
\hline MGIT MTB GKÐ (-) & $\mathbf{2}$ & 1,89 & $\mathbf{9 6}$ & 90,57 & $\mathbf{9 8}$ & 92,45 \\
\hline Tống & $\mathbf{9}$ & $\mathbf{8}, 94$ & $\mathbf{9 7}$ & 91,51 & $\mathbf{1 0 6}$ & 100 \\
\hline
\end{tabular}

Kappa giữa 2 phương pháp là $0,81, \mathrm{p}=0,0000$.

Nhân xét: trong 106 bênh nhân được làm đủ 2 phương pháp lây bệnh phẩm, nuôi cấy vi khuẩn lao dương tính chung 7 trường hợp, gây khạc đờm chẩn đoán thêm được 1 trường hợp và NSPQ chẩn đoán thêm được 2 trường hợp. Hai phương pháp lấy bênh phẩm có đồng thuận rất cao trong chẩn đoán với Kappa=0,81.

3.3. Một số đặc điểm của bệnh nhân lao phổi AFB âm tính

3.3.1 Thông tin chung của đôî tượng nghiên cứu

Bảng 6: Tuổi, giới, địa dư của đôi tượng nghiên cứlu

\begin{tabular}{|c|c|c|c|}
\hline \multicolumn{2}{|c|}{ Đặc điểm } & $\begin{array}{c}\text { Số lương } \\
\text { (n=298) }\end{array}$ & $\begin{array}{c}\text { Tỷ lệ̂ } \\
\text { (\%) }\end{array}$ \\
\hline \multirow{4}{*}{ Tuổi } & $\leq 20$ & 5 & 1,7 \\
\cline { 2 - 4 } & $21-30$ & 20 & 6,7 \\
\cline { 2 - 4 } & $31-40$ & 31 & 10,4 \\
\cline { 2 - 4 } & $41-50$ & 26 & 8,7 \\
\cline { 2 - 4 } & $>50$ & 216 & 72,5 \\
\hline \multirow{2}{*}{ Giới } & \multicolumn{2}{|c|}{$61,74 \pm 19,10(15-96)$} \\
\cline { 2 - 4 } & Nam & 204 & 68,5 \\
\hline Nỡ & Thành thị & 94 & 31,5 \\
\hline
\end{tabular}

\begin{tabular}{|c|c|c|c|}
\hline \multirow{2}{*}{ sống } & Nông thôn & 153 & 52,7 \\
\cline { 2 - 4 } & Miền núi & 18 & 6,1 \\
\hline
\end{tabular}

Nhận xét: 298 bênh nhân được thực hiện gây khạc đờm có độ tuổi trung bình là $61,74 \pm$ 19,10 tuổi, trong đó nhóm tuối $\geq 50$ tuổi chiếm đa số $(72,5 \%)$. Có $68,5 \%$ bệnh nhân là nam, $52,7 \%$ đối tượng sinh sống tại nông thôn và $42,2 \%$. Trong nhóm đối tượng nghiên cứu, $52,7 \%$ đối tượng sinh sống tại nông thôn và $42,2 \%$ sống ở thành thị.

\begin{tabular}{|c|c|c|c|}
\hline \multicolumn{2}{|c|}{ Tiền sử } & $\begin{array}{l}\text { Số lượng } \\
(n=298)\end{array}$ & $\begin{array}{l}\text { Tỷ lệ } \\
(\%)\end{array}$ \\
\hline \multirow{2}{*}{ Hút thuốc } & Có & 139 & 46,7 \\
\hline & Không & 159 & 53,4 \\
\hline \multirow{2}{*}{ Nghiện rượu } & Có & 12 & 4,0 \\
\hline & Không & 286 & 96,0 \\
\hline \multirow{2}{*}{$\begin{array}{c}\text { Tiếp xúc với } \\
\text { ngươi mắc lao }\end{array}$} & Có & 19 & 6,4 \\
\hline & Không & 279 & 93,6 \\
\hline
\end{tabular}

Nhận xét: Trong nhóm đối tượng nghiên cứu, $46,7 \%$ có tiền sử hút thuốc ; $4,0 \%$ có tiền sử nghiện rượu và $6,4 \%$ đã từng tiếp xúc với người mắc lao.

3.3.2. Đặc điểm lâm sàng, cận lâm sàng Đặc điểm lâm sàng

Bảng 8. Các triêuu chứng toàn thân và chẩn đoán lao phổi

\begin{tabular}{|c|c|c|c|c|c|c|c|}
\hline \multirow[t]{2}{*}{ Triệu chứng } & \multicolumn{2}{|c|}{$\begin{array}{c}\text { CĐXĐ lao phối } \\
(n=45)\end{array}$} & \multicolumn{2}{|c|}{$\begin{array}{c}\text { Không } \\
(n=253)\end{array}$} & \multicolumn{2}{|c|}{$\begin{array}{c}\text { Chung } \\
(n=298)\end{array}$} & \multirow[t]{2}{*}{$\mathbf{P}$} \\
\hline & $\mathrm{n}$ & Tỷ lệ & $\mathbf{n}$ & $\%$ & $\mathbf{n}$ & $\%$ & \\
\hline Sốt nhẹ & 18 & 40,0 & 67 & 26,5 & 85 & 28,5 & 0,064 \\
\hline Sốt cao & 16 & 35,6 & 95 & 37,6 & 111 & 37,3 & 0,799 \\
\hline Mệt mói & 27 & 60,0 & 109 & 43,8 & 136 & 45,6 & 0,036 \\
\hline Gầy sút & 23 & 51,1 & 83 & 32,8 & 106 & 35,6 & 0,018 \\
\hline Chán ăn & 12 & 26,7 & 60 & 23,7 & 72 & 24,2 & 0,670 \\
\hline Ra mồ hôi trộm & 11 & 24,4 & 35 & 13,8 & 46 & 15,4 & 0,069 \\
\hline
\end{tabular}

Nhận xét: So sánh giữa nhóm chẩn đoán xác định lao phổi và nhóm không mắc lao, triệu chứng mệt mỏi, gầy sút cân và sốt nhẹ là các triệu chứng hay gặp nhất trong nhóm chẩn đoán xác định lao phổi, với tỷ lệ lần lượt là $60,0 \%, 51,1 \%$ và $40,0 \%$. Trong đó, các triệu chứng sốt nhẹ, mệt mỏi, gây sút cân có sự khác biệt có ý nghĩa thống kê giữa hai nhóm với $p<0.05$.

Bảng 9. Các triệu chứng thực thể và chẩn đoán lao phổi

\begin{tabular}{|c|c|c|c|c|c|c|c|}
\hline \multirow{2}{*}{$\begin{array}{l}\text { Triệu chứng cơ năng } \\
\text { và thực thể }\end{array}$} & \multicolumn{2}{|c|}{$\begin{array}{c}\text { CĐXĐ lao phối } \\
(n=45)\end{array}$} & \multicolumn{2}{|c|}{$\begin{array}{c}\text { Không } \\
(n=253)\end{array}$} & \multicolumn{2}{|c|}{$\begin{array}{c}\text { Chung } \\
(n=298)\end{array}$} & \multirow[t]{2}{*}{$\mathbf{P}$} \\
\hline & $\mathrm{n}$ & Tỷ lệ & $\mathrm{n}$ & $\%$ & $n$ & $\%$ & \\
\hline Ho khan & 22 & 48,9 & 121 & 47,8 & 143 & 48,0 & 0,895 \\
\hline Ho đờm & 20 & 44,4 & 135 & 53,4 & 155 & 52,0 & 0,270 \\
\hline Ho ra máu & 4 & 8,9 & 23 & 9,1 & 27 & 9,1 & $1,000^{* *}$ \\
\hline Đau ngực & 17 & 37,8 & 92 & 36,4 & 109 & 36,6 & 0,856 \\
\hline Khó thở & 17 & 37,8 & 129 & 51,0 & 146 & 49,0 & 0,102 \\
\hline
\end{tabular}




\begin{tabular}{|c|c|c|c|c|c|c|c|}
\hline Ran ấm, ran nố & 34 & 75,6 & 186 & 73,5 & 220 & 73,8 & 0,774 \\
\hline Ran rít, ran ngáy & 4 & 8,9 & 44 & 17,4 & 48 & 16,1 & 0,153 \\
\hline Hội chứng 3 giảm & 3 & 6,7 & 28 & 11,1 & 31 & 10,4 & $0,596^{* *}$ \\
\hline
\end{tabular}

Nhận xét. Về triệu chứng cơ năng và thực thể của nhóm chẩn đoán xác định lao phổi, hay gặp nhất là ran ẩm, ran nổ $(75,6 \%)$ và ho đờm $(44,4 \%)$, ít gặp nhất là hội chứng ba giảm (chiếm 6,7\%). Không có triệu chứng thực thể nào có khác biệt thống kể giữa nhóm chẩn đoán xác định lao phổi và nhóm không mắc lao.

\section{Đặc điểm cận lâm sàng}

Bảng 10. Một số đặc điểm X-quang

\begin{tabular}{|c|c|c|c|c|c|c|c|}
\hline \multirow[t]{2}{*}{ Đặc điểm X-quang } & \multicolumn{2}{|c|}{$\begin{array}{l}\text { CĐXĐ lao phổi } \\
(n=45)\end{array}$} & \multicolumn{2}{|c|}{$\begin{array}{c}\text { Không } \\
(n=253)\end{array}$} & \multicolumn{2}{|c|}{$\begin{array}{c}\text { Chung } \\
(n=298)\end{array}$} & \multirow[t]{2}{*}{$\mathbf{p}$} \\
\hline & $\mathbf{n}$ & $\%$ & $\mathbf{n}$ & $\%$ & $\mathbf{n}$ & $\%$ & \\
\hline Thâm nhiềm & 33 & 73,3 & 130 & 51,4 & 163 & 54,7 & 0,006 \\
\hline Nốt & 17 & 37,8 & 63 & 24,9 & 80 & 26,9 & 0,072 \\
\hline Hang & 8 & 17,8 & 32 & 12,7 & 40 & 13,4 & 0,352 \\
\hline Đông đặc & 29 & 64,4 & 127 & 50,2 & 156 & 52,4 & 0,078 \\
\hline Xơ vôi & 1 & 2,2 & 32 & 12,7 & 33 & 11,1 & 0,040 \\
\hline Tràn dịch màng phổi & 14 & 31,1 & 60 & 23,7 & 74 & 24,8 & 0,290 \\
\hline \multicolumn{8}{|c|}{ Mức độ tổn thương } \\
\hline Độ I & 19 & 42,2 & 68 & 26,9 & 87 & 29,2 & \multirow{3}{*}{0,113} \\
\hline Độ II & 22 & 48,9 & 155 & 61,3 & 177 & 59,4 & \\
\hline Độ III & 4 & 8,9 & 30 & 11,9 & 34 & 11,4 & \\
\hline \multicolumn{8}{|c|}{ Vị trí tổn thương tập trung } \\
\hline Trên & 32 & 71,1 & 208 & 82,2 & 240 & 80,5 & 0,083 \\
\hline Dưới & 27 & 60,0 & 127 & 50,2 & 154 & 51,7 & 0,225 \\
\hline Lan tỏa & 6 & 13,3 & 44 & 17,4 & 50 & 16,8 & 0,502 \\
\hline
\end{tabular}

Nhận xét: Thâm nhiễm, đông đặc, tổn thương độ II, ở vị trí trên là những đặc điểm hay gặp nhất trong nhóm chẩn đoán xác định lao phổi, với tỷ lệ lần lượt là $73,3 \%, 64,4 \%, 48,9 \%$ và $71,1 \%$. Có sư khác biêt có ý nghĩa thống kê giữa nhóm chẩn đoán xác định lao phổi và nhóm không mắc lao về đặc điểm thâm nhiễm và xớ vôi với $p<0.05$. Không có sự khác biệt thống kê giữa hai nhóm này về mức độ tổn thương và vị trí tổn thương.

\section{BÀN LUẬN}

4.1. Kỹ thuật gây khạc đờm. Tỷ lệ thành công: tỷ lệ thành công của kỹ thuật GKĐ trong nghiên cứu của chúng tôi là rất cao đạt $98.1 \%$ (303/309 BN). Các nghiên cứu khác trên thế giới cũng cho thây tỷ lệ thành công của kỹ thuật rất cao khoảng $70 \%$ đến $100 \%$ khi sử dụng nước muối ưu trương đi kèm với máy khí dung siêu âm, trong khi đó nếu dùng máy khí dung khí nén thì tỷ lệ thành công rất thấp [1]. Sự khác biệt do máy khí dung siêu âm tạo được dòng ra với lưu lượng đủ lơn, các hạt có kích thước đều, nhỏ hởn, phân bố tốt hơn ở các phế quản tận, từ đó hiệu quả gây ho khac đờm tốt hơn cả về số lượng bệnh phẩm, lấn chất lượng bệnh phẩm. Trên thực tế lâm sàng hiện nay còn không ít các cơ sở y tễ vẫn đang sử dụng máy khí dung khí nén để gây khạc đờm, dẫn tới tỷ lệ thành công của kỹ thuật không cao. Vì vậy, qua nghiên cứu này một lần nữa chúng tôi nhấn mạnh khuyến cáo nên sử dung máy khi dung siêu âm để làm tăng tỷ lệ thành công của kỹ thuật gây khạc đờm.

Về tính chất bệnh phẩm lấy được, nghiên cứu của chúng tôi cho thây có $38,9 \%$ bệnh phẩm trong. Bệnh phẩm trong tính chất tương tự như dịch rửa phế quản phế nang trong soi phế quản ở những trường hợp không có viêm mủ. Tính chất này thường gặp ở bệnh nhân lao AFB âm tính do ít phá huỷ và tải lượng vi khuẩn thấp. Vì vậy, cần có sự thông báo, trao đổi giữa lâm sàng với phòng xét nghiệm, tránh loại bỏ bệnh phẩm vì đờm không phải đờm mủ. Theo kinh nghiệm của chúng tôi là ghi rõ trên nhãn bệnh phẩm và giấy chỉ định là "đờm khí dung".

Chúng ta đã biết rằng nước muối ưu trương có thể gây co thắt phế quản. Cơ chế gây co thắt có thể do nồng độ Osmol cao làm mất nước tế bào niêm mạc đường hô hấp gây phản ứng $\mathrm{co}$ thắt. Nghiên cứu chúng tôi gặp tỷ lệ có biến chứng là $13,6 \%$ trong đó $88,1 \%$ là khó thở nhe, không có bệnh nhân tử vong. Khi gặp các biến chứng, dừng khí dung nước muối ưu trương, một số trường hợp phải thở oxy, khí dung 
ventolin. Có thể nói GKĐ là môt kỹ thuât khá an toàn, tuy nhiên chúng ta luôn phải đề phòng nguy cơ co thắt phế quản bằng cách chuẩn bị sẳn phương tiện, thuốc và vật tư y tế để xử trí nếu biến chứng xảy ra. Bên canh đó việc khám sàng lọc trước khi làm thủ thuật và theo dõi trong suốt quá trình làm thủ thuật là rất quan trọng.

Giá trị của kỹ thuật GKĐ. Kỹ thuật GKĐ có hiêu quả cao trong chẩn đoán lao phổi, đặc biệt là lao phổi AFB (-) hoặc những bệnh nhân không khạc được đờm tự nhiên tương đương với nội soi phế quản cao hơn khạc đờm tư động và nội soi lây dịch dạ dày. Trong nghiên cứu của chúng tôi GKĐ đồng thuận rất tốt với NSPQ với Kappa= 0,81 trong chẩn đoán lao phổi. Vì vậy, nếu chỉ để lấy bệnh phẩm để chẩn đoán nguyên nhân vi sinh (bao gồm lao và các nhiễm trùng hô hấp khác) thì nên ưu tiên kỹ thuật GKĐ hơn là nội soi phế quản nhằm giảm thủ thuật xâm lấn, tiết kiệm và giảm phơi nhiễm.

4.2. Đăc điểm lâm sàng. Lâm sàng bênh nhân lao phổi $\mathrm{AFB}(-)$ cũng nằm trong bệnh cảnh lao phổi nói chung. Đặc điểm lâm sàng của lao phổi rất đa dạng và không đặc hiệu. Tuy nhiên, có một số dấu hiệu hướng tới chẩn đoán lao phối như: sốt nhẹ về chiều, có khi sốt cao, ra mồ hôi trộm về đêm, mệt mỏi, ăn ngủ kém, gây sút cân. Kèm theo bệnh nhân ho khạc đờm, ho ra máu, đau tức ngực, khó thở [2].

Bệnh nhân bị lao phổi AFB âm tính thường ít nhiễm trùng hơn, tổn thương phổi ít hơn và có tỷ lệ tử vong thấp hơn, khả năng lây truyền kém hơn. Biểu hiện lâm sàng của lao phổi AFB âm tính thường thường nghèo nàn. Chẩn đoán xác định lao phổi $A F B$ âm tính còn khó khăn và phức tạp và thường phải dựa vào kỹ thuật hiện đại tốn kém. Trong nghiên cứu của chúng tôi, mẹt mỏi, gầy sút cân và sốt nhẹ về chiều là các triệu chứng cơ năng hay gặp nhất trong nhóm lao phổi hoạt động, với tỷ lệ lần lượt là $60,0 \%$, $51,1 \%$ và $40,0 \%$. Trong đó, các triêu chứng sốt nhe, mệt mỏi, gầy sút cân có sự khác biệt có ý nghĩa thống kê giữa hai nhóm với $p<0.05$. Về triệu chứng thực thể của nhóm chẩn đoán xác định lao phổi, hay gặp nhất là ran ẩm, ran nổ $(75,6 \%)$ và ho đờm $(44,4 \%)$, ít gặp nhất là hội chứng ba giảm (chiếm $6,7 \%$ ). Tuy các triệu chứng lâm sàng chỉ có giá trị định hướng cho chẩn đoán nhưng rất cần thiết, đặc biệt là ở tuyến y tế cơ sở. Trong nghiên cứu của Harries A.D (2001), tỷ lệ chẩn đoán lao phổi AFB (-) dựa vào tiêu chuẩn lầm sàng chiếm $78 \%$ [3].

\section{3. Đặc điểm cận lâm sàng}

X quang. Phân tích triệu chứng cận lâm sàng cho thấy có sự khác biệt có ý nghĩa thống kê về hình ảnh thâm nhiễm và xơ vôi trên Xquang ở nhóm được chẩn đoán lao hoat động so với nhóm xét nghiêm tìm lao âm tính, dù lao AFB âm tính thường ít triệu chứng vì nồng độ vi khuẩn thấp [4].

Theo chương trình chống lao quốc gia, khi có ít nhất 2 mẫu đờm AFB (-), người bênh được chẩn đoán lao phổi AFB (-) cân thoả mãn 1 trong 2 điều kiện sau: 1) Có bằng chứng vi khuẩn lao trong đờm, dịch phế quản, dịch dạ dày bằng phương pháp nuôi cấy hoặc các kỹ thuật mới như Xpert MTB/RIF. 2) Được thầy thuốc chuyên khoa chẩn đoán và chỉ định một phác đồ điều trị lao đây đủ dựa trên (i) lầm sàng, (ii) bất thường nghi lao trên Xquang phổi và (iii) thêm 1 trong 2 tiêu chuẩn sau: HIV (+) hoặc không đáp ứng với điều trị kháng sinh phổ rộng.

Ở Viêt Nam năm 2006 Đồng Khắc Hưng và cộng sự nghiên cứu trên 30 bênh nhân lao phổi AFB (-), nuôi cấy $(+)$ cho thấy các kết quả thu được cho thây: lao phổi AFB đờm (-) thường xuất hiện ở người già, khởi phát lặng lẽ, thường ho khan, tổn thương $X$ quang ít phá huỷ hơn so với lao phổi AFB đờm (+) [5].

\section{KẾT LUÂ̂N}

Kỹ thuật gây khạc đờm là một kỹ thuật khá an toàn, tỷ lệ lấy được bệnh phẩm rất cao, và đồng thuận rất tốt với nội soi phế quản trong chẩn đoán lao phổi AFB âm tính. Một số triệu chứng lâm sàng và cận lâm sàng có giá trị trong chẩn đoán lao phổi AFB âm tính là: mệt mỏi, gây sút cân, ra mồ hôi trộm, $X$ quang có hình ảnh thâm nhiễm và xơ vôi.

\section{TÀI LIÊU THAM KHẢO}

1. Hunter, C.J., et al., The safety and success rate of sputum induction using a low output ultrasonic nebuliser. Respiratory Medicine, 1999. 93(5): p. 345-348.

2. Rossman, M.D. and R.L. Mayock, Pulmonary tuberculosis, in Tuberculosis and Nontuberculosis Mycobacterial Infections, M.H. Press, Editor. 2006: New York.

3. Harries, A., et al., Clinical diagnosis of smearnegative pulmonary tuberculosis: an audit of diagnostic practice in hospitals in Malawi. 2001. 5(12): p. 1143-1147.

4. Colebunders, R. and I. Bastian, A review of the diagnosis and treatment of smear-negative pulmonary tuberculosis. Int J Tuberc Lung Dis, 2000. 4(2): p. 97-107.

5. Hưng, Đ.K., Đ. Quyết, and N.V. Thiêm, Nghiên cứu lầm sàng lao phổi AFB đờm âm tính Tạp chí $Y$ - Dược y học Quân sự, 2006. 3. 